\title{
A Study on Computational Analysis of Smoke Movement in Indoor Complex Gymnasium
}

\author{
Chan-sol Ahn, Jung-yup Kim \\ Fire Research Institute, Korea Institute of Civil Engineering and Building Technology \\ 283, Goyang-daero, Ilsanseo-gu, Goyang-si, Gyeonggi-do, Republic of Korea \\ chansole@kict.re.kr; jykim1@kict.re.kr
}

\section{Extended Abstract}

In Korea, the level of national welfare has been continuously improved, and the perception of the nation has been steadily improving. As a result, the demand for physical education related welfare facilities is continuously increasing, and construction of indoor complex gymnasium is also increasing. In addition, the number of users of sports facilities is rapidly increasing, and the structure of gymnasiums is designed to be huge and complicated. However, these tendencies can be seriously threatened by the occurrence and spread of smoke when a fire occurs. This study is a numerical analysis of the behavior of smoke at the indoor complex gymnasium under construction. The results of this analysis will be used to predict the fire risks to users of indoor complex gymnasiums and to plan safe evacuation of users. In order to carry out this study, a previous study on the design of smoke control systems for large spaces[1] and evacuation stairs[2] was referenced. Numerical studies on smoke diffusion[3] and smoke filling[4 6] in large spaces were also referenced.

In order to numerically analyze the smoke behavior inside the complex gymnasium, a 4-story indoor complex gymnasium under construction was selected. The gym has an area of 4,981 $\mathrm{m}^{2}$ and a total floor area of 10,284 $\mathrm{m}^{2}$. The sports facilities include a martial art training center, a physical training center, a seminar room, and a shower room on the first basement level, and a multipurpose gymnasium (basketball, volleyball, handball), a player waiting room and a judging waiting room are installed on the first floor. There are grandstand and jogging track from the second floor to the third floor.

In this study, $67.6 \mathrm{~m} \times 78.2 \mathrm{~m} \times 20.7 \mathrm{~m}$ analytical boundaries were set for the modeling of the smoke behavior of the gymnasium, and $169 \times 180 \times 67$ grids were used. The standard atmospheric conditions at $20{ }^{\circ} \mathrm{C}$ were used for the numerical analysis and the ignition source was set to burn $10 \mathrm{MW}$ of heptane in the underground seminar room. In order to analyze the evacuation activities of the users, 500 people were randomly assigned to each floor and a total of 2000 people were set to reside in the complex gymnasium. FDS (Fire Dynamics Simulator)+Evac 6.3.2 was used to predict the generation and spread of smoke after the fire, and the LES model was used for the turbulence analysis. The numerical analysis was conducted to analyze the smoke spread for a total of 30 minutes.

Through this analysis, the smoke height of each floor was predicted and the risk of exposure to toxic gas was analyzed. As a result, the height of toxic gas $(0.7 \mathrm{~m}$ and $1.3 \mathrm{~m})$ in the evacuation corridor on the 1 st floor was lower than the height of toxic gas $(2.4 \mathrm{~m})$ in the basement where the fire occurred. This means that the user on the first floor escape route is exposed to more toxic gas than the user in the basement where the fire occurred. As a result of analyzing the evacuation routes of users, it was analyzed that the number of bottlenecks accumulated by 830 persons instantaneously increased with the increase of 2.8 persons per minute in the path of the stairs where the users of the second and third floors moved to the first floor. This means that the path from the 2 nd and 3rd floor to the 1st floor is needed more than the current design.

This work was supported by the National Research Council of Science \& Technology (NST) grant by the Korea government (MSIP) (No. CRC-16-02-KICT)

\section{References}

[1] C. S. Ahn, J. Y. Kim, "A Study for Estimation of Ventilation Capacity of Large Enclosure Considering Real Fire Load," in Pedestrian and Evacuation Dynamics, pp. 1187-1195, 2012.

[2] J. Y. Kim, H. J. Shin, J. S. Kim, "Development of Smoke Control System Ensuring Safe Evacuation Through Stairwell for High-Rise Building in Korea," in Pedestrian and Evacuation Dynamics, pp. 213-221, 2012. 
[3] C. Jianguo, C. Haixin, F. Song, "Two typical phenomena from the numerical simulation of fire and smoke transport in a gymnasium fire," Chinese Science Bulletin, vol. 51, no. 12, pp. 1521-1525, 2006.

[4] C. L. Chow, S. S. Han, "Simulation of Atrium Smoke Filling by Computational Fluid Dynamics," International Journal of Ventilation, vol. 8, no. 4, pp. 371-384, 2010.

[5] S. Kerber, J. A. Milke, "Using FDS to Simulate Smoke Layer Interface Height in a Simple Atrium," Fire Technology, vol. 43, no. 1, pp. 45-75, 2007.

[6] A. Rafinazari, G. Hadjisophocleous, "Full-Scale Tests and CFD Modeling to Investigate the Effect of Opening Arrangement on Smoke Layer Height in Atrium Fires," Fire Science and Technology, pp. 793-800, 2015. 